\title{
The Method of Washing Face Mask is Controversial
}

\author{
Kashiko Fujii* \\ Nagoya University, School of Health Sciences, Japan \\ *Corresponding author: Kashiko Fujii, Nagoya University, School of Health Sciences, 1-1-20 Daikou Minami Higashi-ku \\ Nagoya-city, Aichi, Japan
}

\begin{tabular}{lll}
\hline ARTICLE INFO & & ABSTRACT \\
\cline { 1 - 1 } $\begin{array}{l}\text { Received: 幽 April 27, } 2020 \\
\text { Published: 幽 May 05, } 2020\end{array}$ & & $\begin{array}{l}\text { Citation: Kashiko Fujii, The Method of Washing Face Mask is Controversial. Biomed J } \\
\text { Sci \& Tech Res 27(3)-2020. BJSTR. MS.ID.004504. }\end{array}$ \\
\hline
\end{tabular}

\section{Opinion}

In Japan, the spread of coronavirus disease 2019 (COVID-19) is becoming more serious. In April 2020, an emergency declaration was issued nationwide, and people have been encouraged to stay home and refrain from outside activity. In February, during the period when hay fever became prevalent, I saw many people wearing masks. As COVID-19, which began in Wuhan, has spread not only in Asian countries, such as Japan, China, South Korea, and Taiwan [1], but also in the United States and Europe, more people are wearing masks. Currently, most people wear masks. It is hard to find the person who do not wear the mask on the street. In Japan, there has been a shortage of nonwoven masks on the market for the past two months, making it difficult to purchase them at local stores. Some people are lined up in front of pharmacies seeking masks beginning early in the morning. Just recently, some companies urgently have started to produce more masks. Now, the lack of surgical and N95 masks at medical institutions is also a serious problem. Despite this situation, some incidents of corrupt politicians or people who sold masks at high prices or sent them to his affiliate with high prices were found. Mask production and supply are not keeping up with actual demand, creating a small supply. The Japanese government decided to distribute 2 cloth masks per household, and some people have received them by mail. However, the budget of $\$ 431$ million (46.6 billion yen) that was used was controversial [2]. The masks which were delivered to many households, however, many defects of the masks were reported from the people who received from the government via post mail. Some companies related to the delivery are now collecting those masks.

Although nosocomial infection due to corona virus are serious issue in many hospitals in Japan, there is a tremendous shortage of medical masks and protective medical wears at medical institutions. Eventually, raincoats and plastic bags are used in some hospitals in replace of protective medical wears. People make every effort to procure masks. Some people make masks with handkerchiefs, socks, or cloth, and some put kitchen paper or gauze between the mouth and cloth masks for further protection. Some people wash nonwoven masks many times, even if the original effectiveness might be weakened due to multiple washings. There are some studies regarding the effectiveness of face masks in the time of influenza, however there were no solid evidence on the effectiveness $[3,4]$. A study comparing health-care workers wearing cloth masks or medical masks noted problems with cloth masks based on infection rate results [5]. Another study on SARSCoV-2 concluded that both surgical and cotton masks seems to be ineffective for prevention at coughs by infected patients [6]. Due to the shortage of masks in the market, people use nonwoven mask or cloth mask by washing, however, mask-washing methods are also inconsistent. Evidence repots are also very limited. Ministry of Economy, Trade and Industry and Ministry of Health, Labor and Welfare provided an image of how to wash the masks with the cloth masks that were distributed. The last step involves soaking the mask in chlorine bleach and rinsing well. Chlorine bleach may cause respiratory or skin damage, raising a concern if you do not use it in proper way. Based on my experience of having light respiratory problem when cleaning the house with chlorine bleach. One of my acquainting professors in Japan introduced me to a Nature 2016 publication [7] of an experiment in which a piece of surgical mask was coated with sodium chloride salt, and high effectiveness was proven. However, these masks have not yet on the market. it seems to me that it is safer for me to coat with salt water in the last washing step, however, again, the effects of nonwoven mask decline due to multiple washing. 
Are people aware that prevention is not just a matter of relying on masks? Even if individuals procure masks in any way, if they touch the mask surface, infection may result. Masks are effective in preventing the spread of respiratory particles and sputum containing the virus to other people. However, despite wearing a mask, an individual may still inhale the fine-particle aerosol and sputum containing the virus, which might diffuse and remain in the air for a long time in poorly ventilated places, from others. COVID-19 is transmitted through infected items; therefore, handwashing important. The history of mask use shows that masks were first used during the Spanish flu of 1918 [8], with gauze and nonwoven masks becoming popular later. People may have learned that wearing a mask has some effect when a Spanish flu became prevalent in Japan, when approximately 390,000 to 450,000 people died. According to a literature review, infections spread in densely populated areas such as the army [9], and people were officially notified to wear the masks [8]. Over approximately 100 years, test kits or vaccines were developed; however, the recommendations by Japanese health authorities were similar ones. They recommended primary measures, such as masks, gargling, and inoculation, via printed words, such as newspapers, posters and leaflets [8]. Now, we also need to be aware of basic methods to maintain health and strengthen the immune system, such as nutrition, sleep, and exercise. And, our world need evidence-based study of cleaning mask and develop reliable masks. Otherwise, people in the future will encounter the same kinds of problems despite the development of vaccine or medicine. Finally, I would like to stress that polymerase chain test (PCR) for corona should be conducted more in Japan. The confirmation of people who are infected would lead to prevent the further spread of infection. Japan is one of lowest levels of testing in OECD countries [10].

\section{References}

1. Feng S, Shen C, Xia N, Song W, Fan M, et al. (2020) Rational use of face masks in the COVID-19 pandemic. The Lancet Respiratory Medicine.

2. https://mainichi.jp/english/articles/20200416/ $\mathrm{p} 2 \mathrm{~g} / 00 \mathrm{~m} / 0 \mathrm{na} / 065000 \mathrm{c}$. The Mainichi Japan, April 16, 2020. Accessed as $2020 / 04 / 25$

3. Cowling B, Zhou Y, Ip D, Leung G, Aiello A (2010) Face masks to prevent transmission of influenza virus: a systematic review. Epidemiol Infect 138(4): 449-456.

4. Canini L, Andréoletti L, Ferrari P, D’Angelo R, Blanchon T, et al. (2010) Surgical mask to prevent influenza transmission in households: a cluster randomized trial. PLoS One 5(11).

5. MacIntyre CR, Seale H, Dung TC, Hien NT, Nga PT, et al. (2015) A cluster randomised trial of cloth masks compared with medical masks in healthcare workers. BMJ open 5(4): e006577.

6. Bae S, Kim MC, Kim JY, Cha HH, Lim JS, et al. (2020) Effectiveness of Surgical and Cotton Masks in Blocking SARS-CoV-2: A Controlled Comparison in 4 Patients. Ann Intern Med.

7. Quan FS, Rubino I, Lee SH, Koch B, Choi HJ (2017) Universal and reusable virus deactivation system for respiratory protection. Sci Rep 7(1): 1-10.

8. GW Rice EP (1993) Pandemic influenza in Japan, 1918-19: mortality patterns and official responses. In: GW Rice, E Palmer (Eds.). Journal of Japanese Studies JSTOR.

9. Akihiko Kawana GN, Yuji Fujikura, Yasuyuki Kato, Yasutaka Mizuno, Tatsuya Kondo, et al. Spanish influenza in Japanese armed forces, 19181920. Emerg Infect Dis 13(4): 590-593.

10. To understand the global pandemic, we need global testing - the Our World in Data COVID-19 Testing dataset.
ISSN: 2574-1241

DOI: 10.26717/BJSTR.2020.27.004504

Kashiko Fujii. Biomed J Sci \& Tech Res

(c) (i) This work is licensed under Creative

Submission Link: https://biomedres.us/submit-manuscript.php

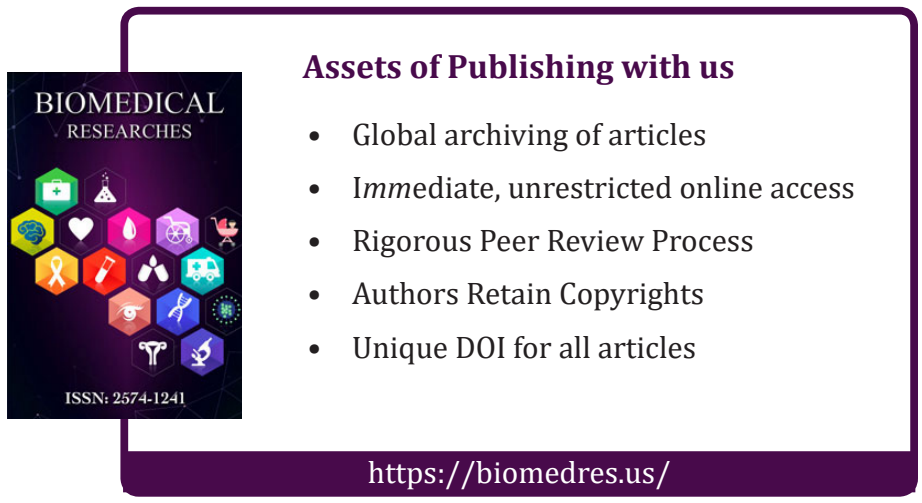

